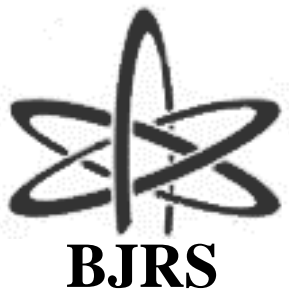

\author{
BRAZILIAN JOURNAL \\ $\mathrm{OF}$ \\ RADIATION SCIENCES \\ 07-02A (2019) 01-08
}

\title{
Analysis of thyroid absorbed dose in cervical CT scan with the use of bismuth shielding
}

\author{
F. S. Santos ; ; A. M. L. Gómez ${ }^{\text {a }}$ P. C. Santana ${ }^{\text {b }}$ C. A. M. Silva ${ }^{a}$; A. P. Mourão ${ }^{a, c}$ \\ ${ }^{a}$ Departamento de Engenharia Nuclear, Universidade Federal de Minas Gerais, 31270-970, Belo Horizonte, MG, \\ Brasil \\ ${ }^{b}$ Departamento de Anatomia e Imagem/Faculdade de Medicina, Universidade Federal de Minas Gerais, 30130-100, \\ Belo Horizonte, MG, Brasil \\ ${ }^{c}$ Centro de Engenharia Biomédica, Centro de Educação Tecnológica de Minas Gerais, 30421-169, Belo Horizonte, \\ $M G$, Brasil \\ fernanda.stephaniebh@yahoo.com.br
}

\begin{abstract}
The Computed Tomography (CT) has become an important tool to diagnose cancer and to obtain additional information for different clinical questions. Today, it is a very fast, painless and noninvasive test that can be performed high quality images. However, CT scan usually requires a higher radiation exposure dose than a conventional radiography examination. The aim of this study is to determine the dose variation deposited in thyroid and in nearby radiosensitive organs, such as: lenses, pharynx, hypophysis, salivary gland and spinal cord with and without the use of bismuth shielded. A cervical CT scan was performed on anthropomorphic male phantom model Alderson Rando, using a GE scanner, Discovery model with 64 channels. Dose measurements have been performed by using radiochromic film strips to register the individual doses in the organs of interest. The results show us that the thyroid received the highest dose, $24.70 \mathrm{mGy}$, in the phantom, according to the incidence of the primary X-ray beam.
\end{abstract}

Keywords: Computed Tomography; Dosimetry; Bismuth shielding.

ISSN: 2319-0612

Accept Submission: 2018-10-30 


\section{INTRODUCTION}

The Computed tomography (CT) is the most common technique used for diagnostic purpose. It is a very fast test that can be performed high quality images. However, the increasing demand for CT had a considerable impact on doses provided to patients and on the exposure of the population as whole [1]. In fact, the worldwide average annual per-capita effective dose from medical procedures has approximately doubled in the past 10-15 years [2]. The dose evaluation in CT is one of many steps that can contribute for reducing patient doses. The cervical CT scans are commonly used for diagnosis of soft tissue, vascular changes, fractures, extent of injuries, dysplasia and other diseases with instability, so it can be associated with a high radiation dose to organs such as thyroid, lenses, salivary gland, pharynx, spinal cord and hypophysis, when compared with conventional radiology. The main objective of this study was to analyze the absorbed doses in a cervical CT scan with and without the use of bismuth shield in the neck.

\section{MATERIALS AND METHODS}

The experiment to observe the reduction dose due to bismuth shield was conducted using a GE CT scanner, Discovery model of 64 channels. An Alderson Rando male anthropomorphic phantom was used to perform a cervical CT scan. This phantom is composed of a human skeleton surrounded by a material, physically and chemically similar to the soft tissues of an adult human body [3]. The torso and head are structured into slices and $2.5 \mathrm{~cm}$ thick. The slices that make up the body phantom have holes that allow placing dosimeters within the phantom [4,5]. Fig. 1 shows the positioning of the male phantom in the gantry isocenter. 
Figure 1: Positioning of the Alderson male phantom in the gantry

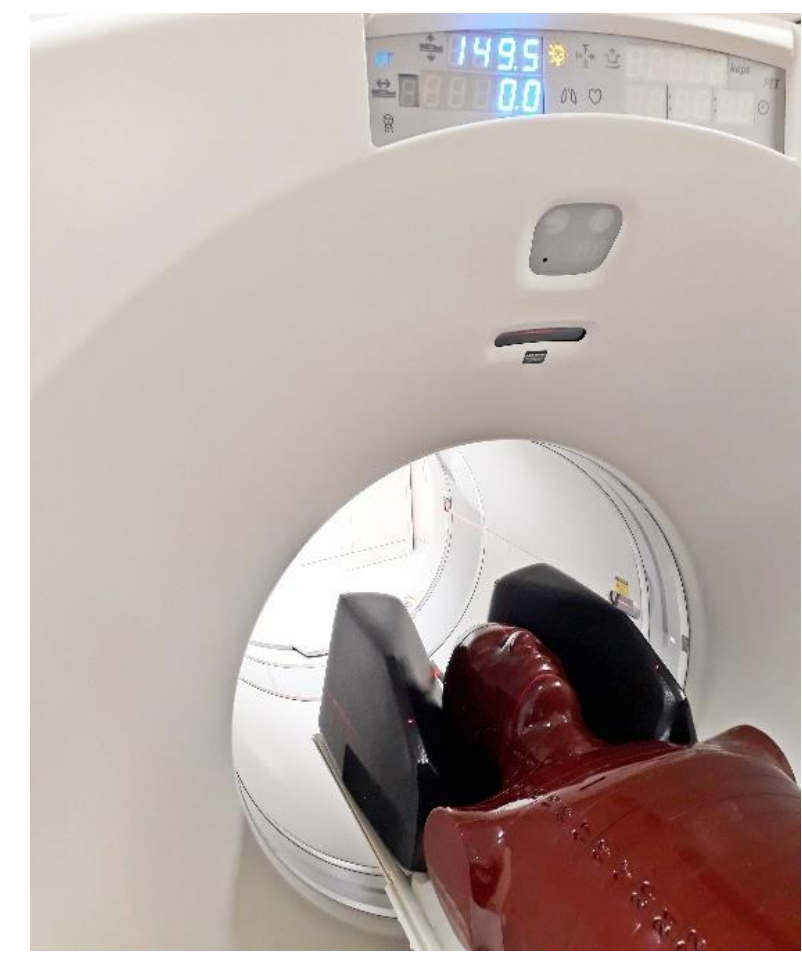

Source: Author

A scout was done to check the correct position of the phantom. The parameters of the protocol used in this study are shown in Table 1.

Table 1: CT scan parameters.

\begin{tabular}{cccccc}
\hline $\begin{array}{c}\text { Voltage } \\
(\mathbf{k V})\end{array}$ & $\begin{array}{c}\text { Electric current } \\
(\mathbf{m A})\end{array}$ & $\begin{array}{c}\text { Time } \\
(\mathbf{s})\end{array}$ & Pitch & $\begin{array}{c}\text { Distance } \\
(\mathbf{m m})\end{array}$ & $\begin{array}{c}\text { Thickness beam } \\
(\mathbf{m m})\end{array}$ \\
\hline 120 & 175 & 0.8 & 0.984 & 200 & 40 \\
\hline
\end{tabular}

Dose measurements have been performed by using GAFCHROMIC XR-CT radiochromic film strips to register the individual doses in the organs of interest such as thyroid, lenses, pharynx, hypophysis, salivary gland and spinal cord, with and without bismuth shield on the neck area (Fig.2). The Fig 3. shows the axial cervical CT images with and without a $1 \mathrm{~mm}$ thick piece of bismuth. 
Figure 2: The phantom Alderson with the bismuth shield on the neck spot and a radiochromic film strip on the right eye

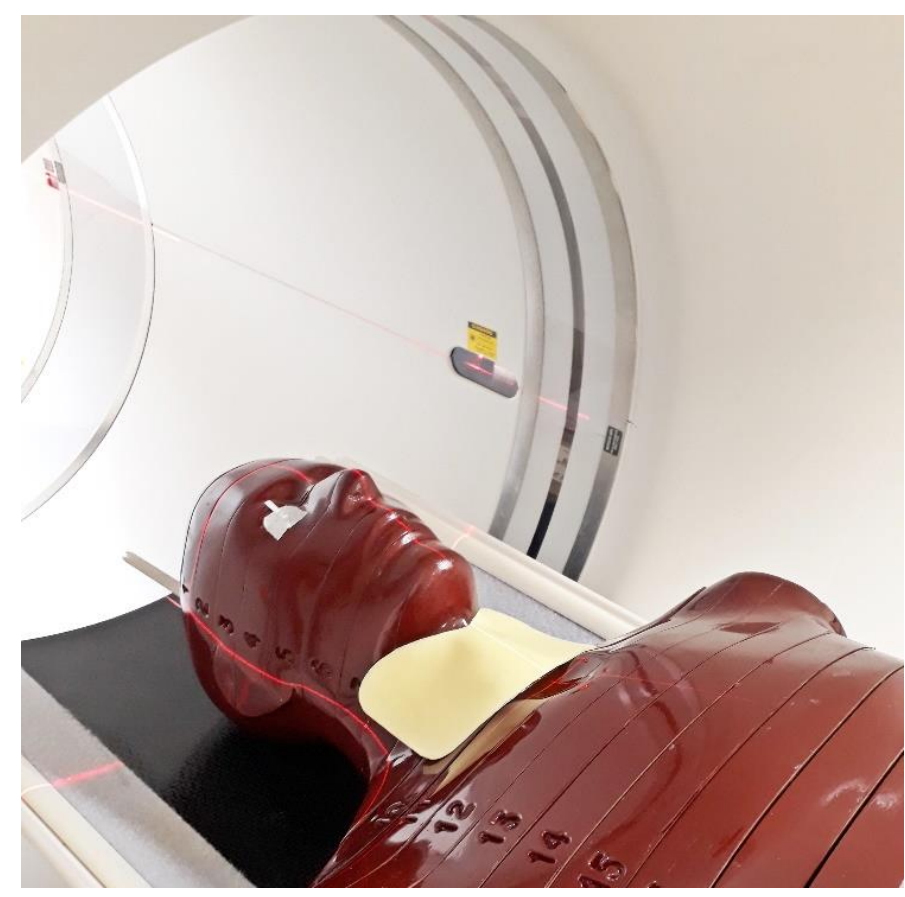

Source: Author

Figure 3: Axial cervical CT images: (a) without and (b) with bismuth shielding over the neck

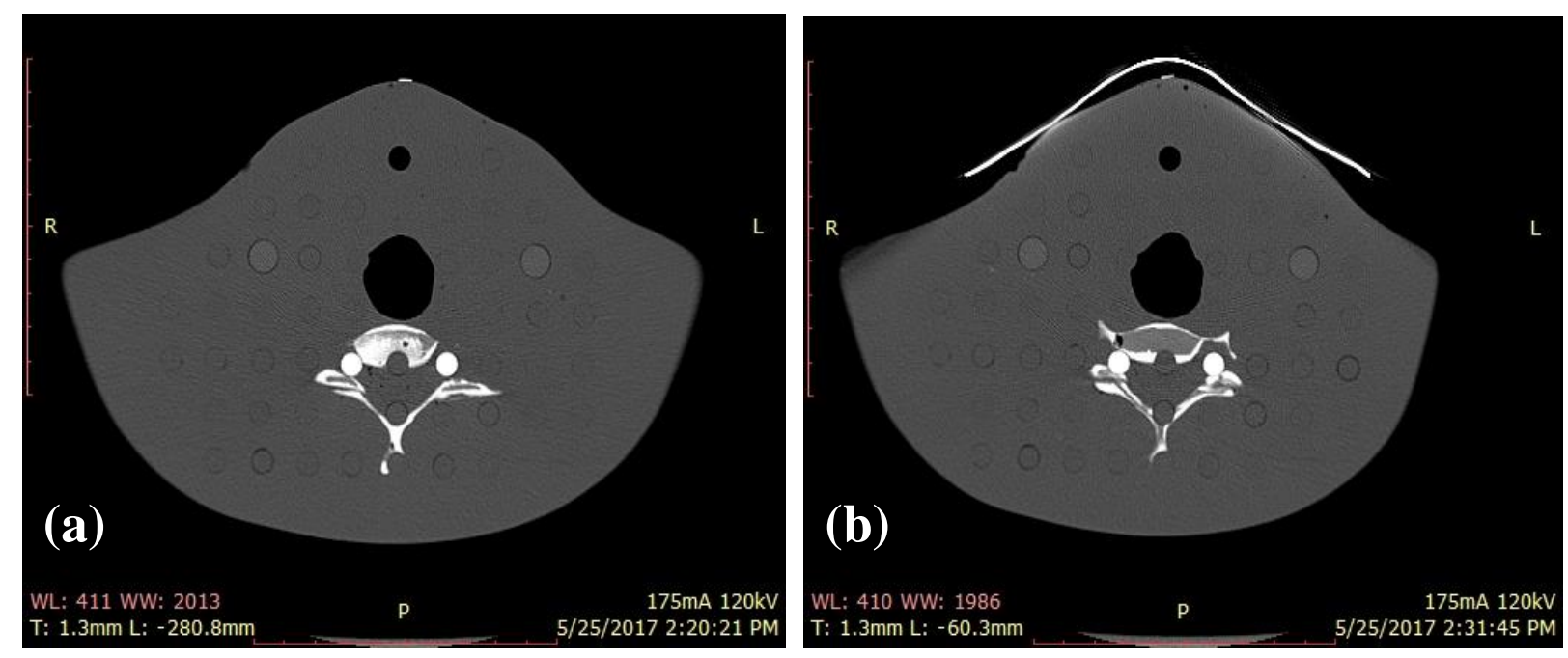

Source: Author 
The radiochromic films are self-developing dosimetry films, insensitive to visible light making it easy to work with during analysis and provide greater spatial resolution in the sub millimeter range (Fig. 4). They have been used extensively in combination with flat bed document scanners to measure patient doses in the $\mathrm{kV}[6,7]$.

Figure 4: Radiochromic film strips: (a) background and (b) exposed.

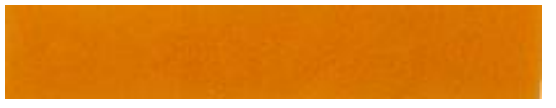

(a)

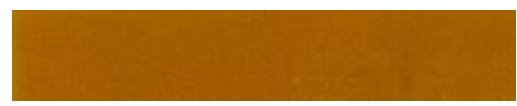

(b)

Source: Author

The exposed films were digitized using a HP Photosmart C4480 reflective type scanner. The scanning parameters used were RGB mode (48 bit) and 300 ppi. The red channel was selected to measurement because these radiochromic films have a main absorption peak in the red region of the visible spectrum (636nm) [6,7].

Metrological reliability of the radiochromic films was demonstrated through homogeneity and repeatability tests and by calibrating it in a reference radiation for CT (RQT9) that were reproduced in the Calibration Laboratory of the Development Center of Nuclear Technology (CDTN/CNEN) $[7,8]$.

\section{RESULTS AND DISCUSSION}

Absorbed doses in the organs positions such as: thyroid, lenses, pharynx, hypophysis, salivary gland and spinal cord are shown in Table 2. T These results allow us to observe that the use of bismuth shield led to a decrease in radiation dose deposited in the thyroid and all organs studied. 
Table 2: Mean absorbed dose in some organ positions in the phantom during cervical CT scans with and without bismuth shielding on neck.

\begin{tabular}{lccc}
\hline Organ position & \multicolumn{2}{c}{$\begin{array}{c}\text { Mean absorbed dose } \\
\text { (mGy) }\end{array}$} & $\begin{array}{c}\text { Dose reduction } \\
(\%)\end{array}$ \\
\cline { 2 - 3 } & $\begin{array}{c}\text { Without bismuth } \\
\text { shielding }\end{array}$ & $\begin{array}{c}\text { With bismuth } \\
\text { shielding }\end{array}$ & \\
\cline { 2 - 3 } Left Lens & 2.96 & 0.82 & 72 \\
Right Lens & 4.24 & 1.02 & 75 \\
Pharynx & 14.55 & 13.57 & 7 \\
Thyroid & 24.70 & 15.09 & 39 \\
Salivary Gland & 23.11 & 19.76 & 15 \\
Spinal Cord & 17.01 & 14.16 & 17 \\
Hypophysis & 6.01 & 4.73 & 21 \\
\hline
\end{tabular}

The highest recorded dose of 24.70 mGy occurred in the thyroid position that stressed the situation of unnecessary radiation exposure. The recorded doses due to scans with and without bismuth shielding showed significant differences; the largest dose reduction of $75 \%$ occurred in the lenses was a consequence of reducing the scattered radiation; the decrease in thyroid dose of $39 \%$ was desired due to the use of bismuth shielding. It is expected that thyroid shielding would degrade image quality and would increase the image noise, however the results of this work suggests that it might be an acceptable procedure to be used for dose reduction mainly during CT examinations that would provide high doses to radiosensitive organs (Fig.3). The use of bismuth shielding is simple and efficient to reduce absorbed doses to the thyroid and nearby organs. The graphic showed in the Fig. 5 allow to observed the influence of bismuth shielding on absorbed doses in the organs studied. 
Figure 5: Influence of bismuth shielding on absorbed doses for some organ positions of the phantom

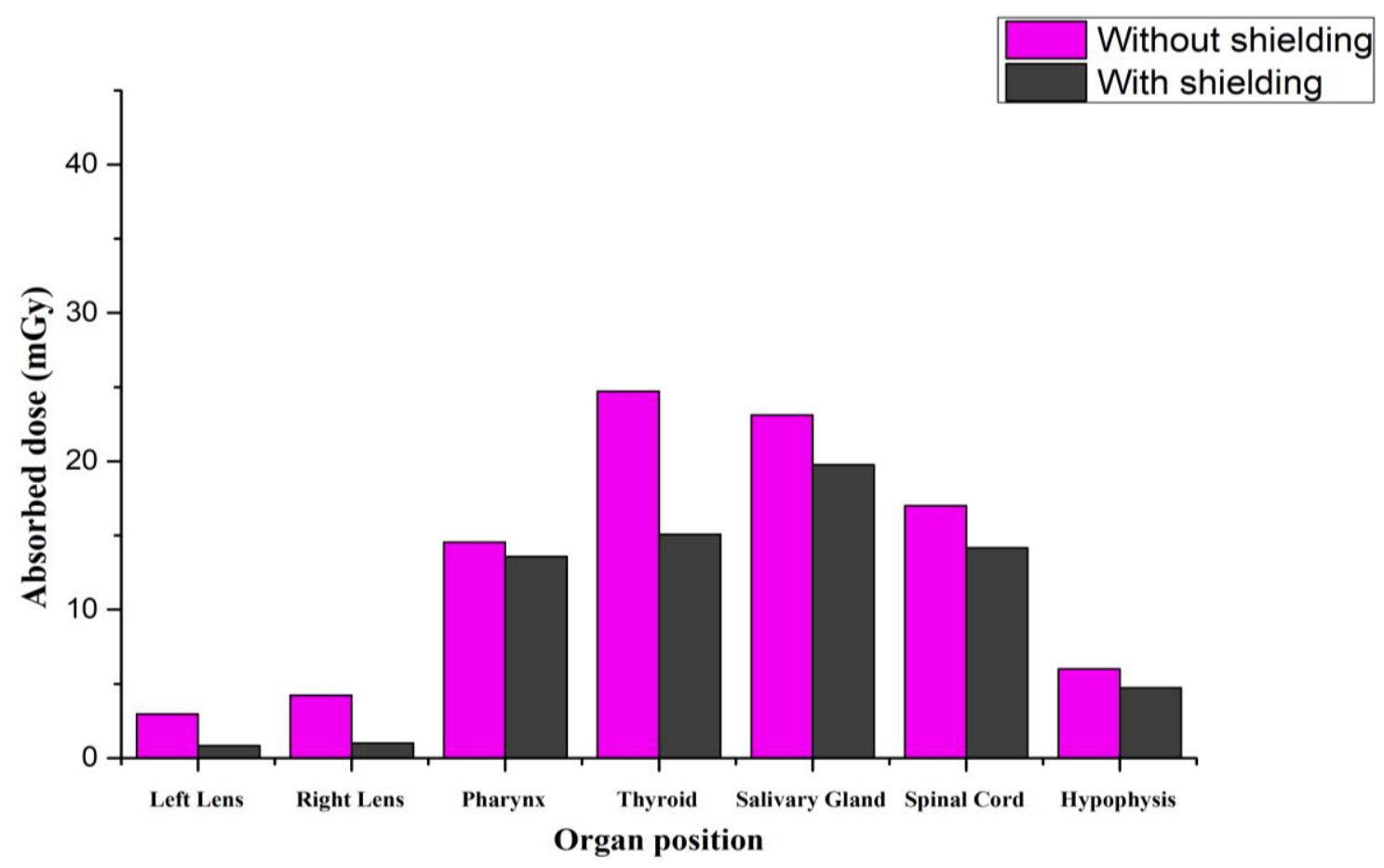

Source: Author

\section{CONCLUSION}

The absorbed doses were determined during a cervical CT scans with and without bismuth shielding on neck of an Alderson Rando male anthropomorphic phantom. Dose values were significantly reduced in all organs of this study and they suggested that the use of bismuth would be, in some cases, a proper procedure for protection as the conditions used for both scans were the same. However, the influence of bismuth on the image quality require future studies.

\section{ACKNOWLEDGMENT}

The authors are grateful to CAPES, CNPq and FAPEMIG for the support. Also, the Technology Center in Nuclear Medicine of UFMG is acknowledged for producing the images and CDTN/CNEN for the use of the phantom. 


\section{REFERENCES}

1. AlONSO, T. C; MOURÃO, A. P; SANTANA, P. C. Assessment of breast absorbed doses during thoracic computed tomography scan to evaluate the effectiveness of bismuth shielding. Applied Radiation and Isotopes, v. 117, p. 55-57, 2016.

2. GOO, H. W. CT radiation dose optimization and estimation: an update for Radiologists. Korean J Radiol, v. 13, p. 1-11, 2012.

3. ALEME, C; LYRA, M. A; MOURÃO, A. P. Evaluation in the use of Bismuth Shielding on cervical spine CT scan using a Male Phantom, In: INTERNATIONAL SYMPOSIUM ON SOLID STATE DOSIMETRY, 2014, Cusco., Peru, p. 664-669.

4. GBElCOVÁ, L; NIKODEMOVA, D; HORVÁTHOVÁ, M. Dose reduction using Bismuth shielding during paediatric CT examinations in Slovakia. Radiation Protection Dosimetry, v. 147, p. 160-163, 2011.

5. COLLETTI, P. M; MICHELI, O. A; LEE, K. H. To shield or not to shield: application of bismuth breast shields. AJR, v. 200, p. 503-507, 2013.

6. GIADDUI, T; CUI, Y. J; GALVIN, W; CHEN, Y; YU, Y; XIAO, Y. Characteristics of Gafchromic XRQA2 films for kV image dose measurement. Medical Physics, v. 39, p. 842-850, 2012.

7. MOURÃO, A. P; ALONSO, T. C; SILVA, T. A. Dose profile variation with voltage in head CT scans using radiochromic films. Radiation Physics and Chemistry, v. 95, p. 254-257, 2014.

8. COSTA, K. C; GOMEZ, A. M. L; ALONSO, T. C; MOURÃO, A. P. Radiochromic film calibration for the RQT9 quality beam. Radiantion Physics and Chemistry, v. 140, p. 370-372, 2017. 